\title{
Innovative urban ecosystems - features of Russian formation and development
}

\author{
Vladimir Okrepilov ${ }^{1}$, Yulia Antokhina ${ }^{1}$, Elena Semenova ${ }^{1}$, and Galina Getmanova ${ }^{1, *}$ \\ ${ }^{1}$ SUAI, Metrological Support of Innovation Technologies and Industrial Security Department, 190121, B. Morskaya st. 67, St. Petersburg, \\ Russia
}

\begin{abstract}
Innovation ecosystem is one of the tools to create conditions that increase the competitiveness of organizations in the national and regional economies. Based on the historical analysis of the formation of the management system in the scientific and technical sphere, carried out by the authors of the article, the elements of the ecosystem that make the main contribution to the overall potential of the Russian economy are considered. Since the main elements of the ecosystem are located in cities - in megalopolises and in specialized settlements - the problem of innovative development and territorial distribution are intertwined more closely than ever, creating both growth points and regions of stagnation. The article considers the types of innovation systems, analyzes the ecosystem approach in innovation policy and the necessary basic conditions for creating local innovation ecosystems.
\end{abstract}

\section{The concept and elements of the innovation ecosystem at the regional level}

The term "innovation ecosystem", which is used to denote a set of elements and processes that determine the development of an innovation sphere, replaced the concept of structure and system (National Innovation System) in 2004 [1]. An ecosystem is a complex selforganizing, self-regulating and self-developing system. It is an open system characterized by incoming and outgoing flows of matter and energy. Changing the terminology indicates that among the elements of the system should be a connection that allows reproducing its actions without the inflow of external resources. At the heart of the concept is the idea of innovation as a process of transforming scientific research into a marketable product or service that requires a lot of concerted efforts of participants: companies, universities, research organizations, venture capital funds [2].

An innovation ecosystem is an environment formed by the participants in the innovation process, in which their interaction takes place, aimed at creating and developing innovations. The basis of the innovation ecosystem are innovators - those who create, develop and promote innovation on the basis of their own motivations, or on the basis of market demand. In addition to innovators, the innovation ecosystem includes various agents who help innovators - investors, corporations and foundations that finance innovation. There are two directions that support the ecosystem - the flow of innovation and the flow of demand for innovation.

The main elements of the innovation ecosystem are:
- science and engineering and technical community [3];

- the venture investment industry;

- innovation infrastructure (incubators, technology parks, innovation centers);

- legislative and legal environment, ensuring the protection of intellectual property;

- steady demand for innovation.

Innovation ecosystem can be seen at various levels from global to local.The innovation potential of the regions of the Russian Federation is extremely unequal. Along with highly developed territories, there are territories without system for creating and implementing innovations and enterprises that could use innovations in its production activities are practically absent. Key institutions, forming a system are located in major cities and satellite towns, attracted to the major metropolitan areas. Such agglomerations have any chance of advancing socio-economic development, pulling both material and human resources from other territories. Innovation is becoming another factor exacerbating the territorial heterogeneity of the country's development level $[4,5]$.

The choice of model of innovative development of the Russian economy requires not only the formation of modern industrial and technological fields, but increase and equalization of living standards in the region. The territorial aspect of innovative development can be analyzed using statistical data that record the dynamics of innovative activity at the level of the constituent entities of the Russian Federation [6]. Moscow occupies a leading place both in terms of developed and used advanced production technologies. Among the leaders in the field of innovative development are also St.

Corresponding author: recchina@mail.ru 
Petersburg, Chelyabinsk region, Moscow region and Sverdlovsk region. From 100 to 200 units advanced production technologies were developed in 2016-2019 in the Republic of Tatarstan, Belgorod Region, Krasnodar Territory, Nizhny Novgorod, Samara, Novosibirsk, Yaroslavl, Novgorod, Irkutsk Regions, Perm and Krasnoyarsk Territories. All cities and regions with high innovative activity have a developed production system and a network of educational and research organizations. That is, we can talk about the emerging ecosystems of these regions [7].

The basis of the territorial innovation ecosystem are: universities and research institutes capable of acting as generators of ideas, new developments and a source of intellectual capital; small innovative enterprises; corporations and companies producing innovative products; venture capital companies; innovation community and technology parks located in the city. Large cities had a natural advantage, since some of the elements had already been created in them during the history of their existence.

\section{The history of innovation management in Russia}

For Russia, changing the development paradigm of the innovation process is a challenge, because this area has always been under strict state control. The territorial innovation infrastructure in the USSR consisted of science, education and implementation centers located in large administrative units, as well as specialized closed cities. They are usually placed institutes, design bureaus and experimental production, conducting research in the military and aerospace sectors.

For example, in the field of aerospace research, this is the city Zhukovsky, which is still the center for the design and testing of aircraft (city status was acquired in 1947), the city Korolev (1938). Its backbone enterprises are the Mission Control Center (as a subsystem of JSC TsNIIMASH) and RSC Energia. The cities of Mirny and Znamensk were built as settlements at the Plesetsk and Kapustin Yar spaceports. This specialization of infrastructure elements was typical until the 60s of the twentieth century, when the main goal was to provide leadership in military technology.

At the end of the 60s, such a territorial organization of the research and development sphere was supplemented by a network of Academgorodoks located in the Urals, Siberia and the Far East. This decision was supposed to accelerate the socio-economic development of the eastern part of the USSR and was, in particular, inspired by N. Khrushchev's visit to Silicon Valley.

At this historical period, the decision was complex and involved the interrelated development of higher education, academic science and design and engineering organizations. It was assumed that the developments carried out in such scientific cities would be, first of all, in demand by the local manufacturing community. This idea has been described as the idea of concentric circles (Fig. 1).

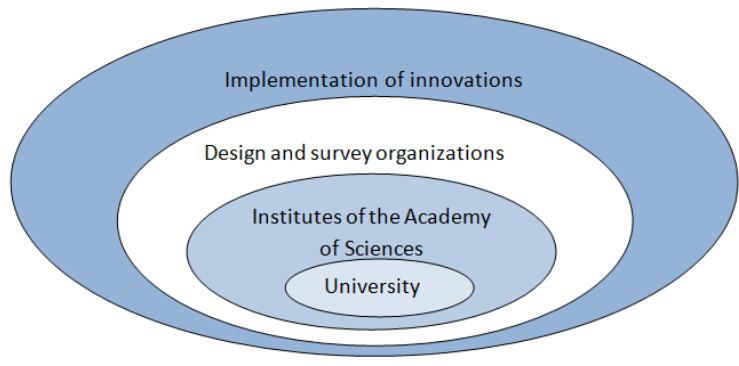

Fig. 1. The concept of concentric circles incorporated in the plans for the creation of zones of special territorial development (Academic towns).

In practice, the situation has developed, which is described by the report of the World Bank, which summed up the analysis of this way of forming an innovative territorial structure. The report noted that two systems independently developed in Russia, which did not use the capabilities and potential of each other.

The industrial sector from time to time sought financial resources for the purchase of technologies and high-tech equipment from abroad and the R\&D sector, which sometimes managed to sell Russian technologies abroad [8]. The heads of the enterprises continued to receive orders and financial resources for the purchase of new technologies and equipment from the Ministry from Moscow.

Regardless of the scientific achievements achieved in Siberian scientific cities, their ties with industry have always been weak, despite the territorial proximity to large industrial centers in which defense plants were located, including electronics and aircraft construction. The division between science and production was such that the Academy of Sciences created its own industrial workshops in Akademgorodok for the production of machines for scientific experiments. At the same time, Novosibirsk electronic factories continued to order research from industry institutes in Moscow. Industrial enterprises were not interested in the latest technologies: their production plans were adapted to the old equipment.

Until the early 2000s, policy focused mainly on supporting academic and industry institutions. But investments in only one or a few elements of the innovation system did not give the desired effect. The task of reforming the system as a whole was set. It turned out that the bottleneck is not research and development, but the transfer of innovations to industry with the aim of their industrial use and scaling. Realization of this fact led to the creation of public and private venture capital companies and a network of business incubators and technology parks.

As a result of this reorganization, cash flows were redirected from the sphere of scientific research to the sphere of implementation and education. Figures 2 and 3 show the structural change in the share of organizations engaged research and implementation from 2000 to 2019. It can be noted that the number of research organizations has decreased by almost $40 \%$, but research units at universities have grown significantly - almost threefold. At the same time, the number of organizations 
that could carry out a pilot introduction and release trial batches of new products has slightly increased.

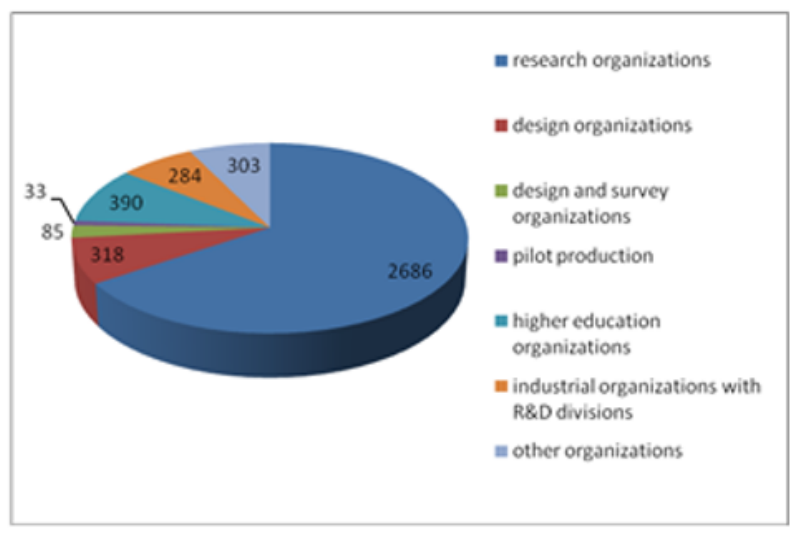

Fig. 2. The number of organizations that performed research and development, by type of organization in the Russian Federation 2000 (units).

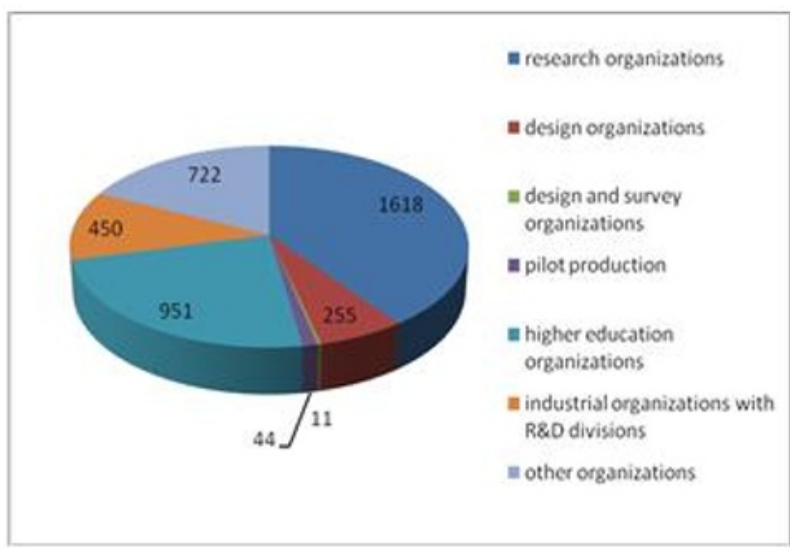

Fig. 3. The number of organizations that performed research and development, by type of organization in the Russian Federation 2019 (units).

Solving the problem of the demand for innovative developments by business organizations faced a number of obstacles. The levers of public administration can be used to modernize, create financial flows and organizational units; they turn out to be practically powerless if it is required to create a system of institutions that stimulate the disclosure of creative and entrepreneurial potential. The lack of growth in the number of small innovative enterprises and the level of innovative activity in general confirm this problem. The success of a particular technology, which usually means making a profit in a competitive international market, takes place outside the walls of the research laboratory, in the social and economic environment of society as a whole. "The Russians do not succeed in this. Where are the Russian Thomas Edison, Bill Gates or Steve Jobs? In fact they are, but you have never heard of them, because they failed miserably when they tried to commercialize their inventions in Russia" - the professor Graham rightly noted [9].

\section{Configuration options for the innovation ecosystem}

An innovative economy presupposes the formation and institutionalization of new technological solutions that oppose it to the "old economy". At the moment in the world there are several practices for the design of the "new economy", which have geographic localization:

- Taking the innovation sector out of the existing economic system with the subsequent introduction of innovative developments into existing production organizations. This approach presupposes a developed venture capital industry that has close ties with manufacturers in various industries. The US venture capital system is organized according to this principle.

- Creation, on the basis of private and public funds, of a system for managing research and development work with the parallel formation of new production clusters. The most striking example of the implementation of this approach is the formation of the Baltic Ring of Technoparks as a prototype of a new economic machine. Scandinavian ideas have spread widely across all OECD countries, which have adapted them to their national and regional specifics [10]. The World Bank experts adhere to a similar approach to organizing innovation processes. The creation of technopolises was also the main trend of the state innovation policy as part of long-term programs for the development and modernization of Chinese science and technology [11]. In Russia, the system of technoparks began to form after V. Putin's visit to Indian Bangalore.

- The system of state scientific and technical orders, carried out by the Ministry of Foreign Trade and Industry of Japan. It is through such a system that state support for the most significant technological projects for the country is carried out.

- In almost all developed countries, specialized implementation organizations are complemented by the presence of $R \& D$ structures within corporations. The more developed industrial production in a particular city, the higher the demand for development and the more powerful the R\&D sector. In Russia, more than $60 \%$ of funds spent on innovation activities are enterprises' own funds. In the early $2000 \mathrm{~s}$, this share was more than $80 \%$. Thus, the innovation ecosystem in Russia at the city level is funded primarily by businesses. Since the activities of technoparks are subsidized from city budgets, it can be concluded that the development of an ecosystem at the city level critically depends on the level of production development.

Nevertheless, the formation of an innovation ecosystem is at the stage of an experiment in modern Russia. All of the above approaches to identifying the "new economy", its support and interaction with the existing economic system are tested.

Pilot projects such as the INO Tomsk Innovation Territorial Center and the Kama Innovation Territorial Production Cluster InnoKam can be considered as successful Russian practices in creating local innovation ecosystems. The projects are jointly implemented by the 
regional authorities and the Government of the Russian Federation within the framework of state programs.

The closest in terms of the creation of local innovation ecosystems are Naukogrady and Closed City SC Rosatom, which combine applied and fundamental science, concentrated in industry research institutes and universities. In these territories, the state provides support measures for the development of science and the socio-economic environment. In a number of territories, infrastructure (technoparks, industrial parks) and organizational foundations (special economic zones, cluster programs, territories of advanced socio-economic development) for the commercialization of scientific developments have been created.

\section{Conclusion}

Russian regions are highly differentiated in terms of quality of life and contribution to the country's innovative development. The analysis revealed a stable dependence - regions with high indicators of quality of life are also donors of innovative development. Low indicators of innovation activity force us to study not only the investment climate, but also social conditions that create the basis for innovative entrepreneurship.

High-tech, knowledge-intensive enterprises cannot successfully function and develop in a vacuum. In modern economies, they are created as part of a larger regional, national, or global value chain. These connections require a thriving sector of large industrial enterprises that produce products with high added value and the availability of conditions for innovative entrepreneurship. Local innovation ecosystems cannot be formed without links with large industrial clusters. The urban innovation ecosystem of Russia needs the simultaneous creation of development institutions and industrial enterprises that would form the demand for innovation.

\section{References}

[1] C.W. Wessner, Entrepreneurship and the Innovation Ecosystem. Policy Lessons from the United States, The Papers on Entrepreneurship, Growth and Public Policy, Germany, 5 (2004)

[2] C. Sarkar, Ph. Kotler The Innovation Ecosystem: New Rules for the Future, The Marketing Journal (12 April 2019)

[3] N.A. Knyazev, R.G. Buyankina, O.V. Letunova, Engineering Basis Of Interaction Of University With Industry And Regional Government, European Proceedings of Social and Behavioural Sciences (EpSBS), 10-16 (2020)

[4] G. Getmanova, M. Smirnova, A. Yastrebov, Analysis of the relationship between the quality of life and the technological development of the regions of the Russian Federation, Proceedings of the International Forum of metrological provision of innovative technologies, St. Petersburg, publishing house SPbSUAI, 165 (2020)
[5] V. Okrepilov, N. Gagulina, G. Getmanova, Taking into account the factors of innovative development of regions in the concept of quality, ICEST 2020 (2020)

[6] Federal State Statistic Service Science and Innovation, The official portal

[7] L.M. Gokhberg (ed.), Rating of innovative development of the constituent entities of the Russian Federation, University Higher School of Economics, 6 (Moscow, NRU HSE, 2020)

[8] From Knowledge to Wealth: Transforming Russian Science and Technology to Create a Modern Knowledge Economy World Bank Report 2002 Innovation, Analytics, Documents

[9] L.R. Graham, Lonely Ideas: Can Russia Compete? (MIT Press, 2013)

[10] I. Ivanova, O. Strand, L. Leydesdorff, The Synergy and Cycle Values in Regional Innovation Systems: The Case of Norway Foresight and STI Governance 13, 1, 48-61(2019)

[11] V. Okrepilov, N. Gagulina, G. Getmanova, Taking into account the factors of innovative development of regions in the concept of quality, European Proceedings of Social \& Behavioural Sciences EpSBS 90 ISSN 2357-1330

[12] M. Castells, The Rise of the network Society (the Informational Age), volume I (Blackwell Publishers Ltd, Oxford UK, 1996)

[13] H. Dou, Ph. Clerc, A. Juillet, Changing Priorities for Strategic Planning from National to Territorial Levels, Foresight and STI Governance 14, 3, 88-99 (2020)

[14] V. Mulas, M. Minges, H. Applebaum, Boosting Tech Innovation Ecosystems in Cities: A Framework for Growth and Sustainability of Urban Tech Innovation Ecosystems, A framework for growth and sustainability of urban tech innovation ecosystems, The World Bank, USA (2015) 